\title{
An Altered Maturation and Adhesion Phenotype of Dendritic Cells in Diseased Individuals Compared to Asymptomatic Carriers of Human T Cell Leukemia Virus Type 1
}

\author{
Sharrón L. Manuel,' Mohit Sehgal,, Zafar K. Khan,, James J. Goedert, ${ }^{2}$ Michael R. Betts, ${ }^{3}$ and Pooja Jain ${ }^{1}$
}

\begin{abstract}
The immunopathogenic mechanisms underlying human T cell leukemia virus type 1 (HTLV-1)-mediated diseases such as adult T cell leukemia (ATL) and HTLV-associated myelopathy/tropical spastic paraparesis (HAM/TSP) are not clearly understood. As critical effectors of antiviral immune response, dendritic cells (DCs) are implicated to play an important role in determining the outcome of HTLV-1 infection. However, a complete understanding of their role in any disease pathogenesis requires extensive assessment of the phenotypic and functional state of DCs. To enable this, we developed a polychromatic antibody cocktail comprising key phenotypic and functional markers of DCs and applied it in a patient cohort from the HTLV-1 endemic region, Jamaica, consisted of seronegative controls, asymptomatic carriers (ACs), ATL, and HAM/TSP patients. This ex vivo analyses included two major subsets of blood DCs, myeloid and plasmacytoid (mDCs and pDCs, respectively). The comparative analyses of results demonstrated a decreased pDC frequency in both ATL and HAM/TSP patients as compared to ACs and seronegative controls. Similarly, CD86 expression on both mDCs and pDCs was significantly higher in HAM/TSP (but not ATL) patients compared to ACs. Interestingly, HLADR expression was significantly lower on $\mathrm{pDC}$ of patients as compared to carriers; however, for mDCs, only the HAM/TSP group had significantly lower expression of HLA-DR. Unlike HAM/TSP individuals, ATL individuals had higher HLA-ABC expression on mDCs compared to ACs. Finally, both mDCs and pDCs of HAM/ TSP patients had significantly higher expression of the programmed death ligand 1 (PD-L1) compared to ACs. Overall, this study suggests that DCs exhibit a differential phenotypic and functional profile between patients (ATL and HAM/TSP) and carriers of HTLV-1 and could provide an important tool for understanding HTLV-1 immunopathogenesis during infection and disease.
\end{abstract}

\section{Introduction}

$\mathbf{H}$ UMAN T CELl LeUKemia virus type 1 (HTLV-1) is an exogenous retrovirus that infects approximately 15-20 million people worldwide, with endemic areas in Japan, the Caribbean, and Africa. ${ }^{1-3}$ The virus spreads through contact with bodily fluids containing infected cells most often from mother to child through breast milk or via blood transfusion. After prolonged latency periods, approximately $3-5 \%$ of HTLV-1-infected individuals develop either adult $\mathrm{T}$ cell leukemia (ATL) or HTLV-associated myelopathy/tropical spastic paraparesis (HAM/TSP). ATL is marked by phenotypic as well as functional abnormalities in $\mathrm{CD}^{+}{ }^{+} \mathrm{T}$ cells that ultimately result in severe immunodeficiency. On the other hand, HAM/TSP is characterized by infiltration of mononuclear cells into the central nervous system followed by demyelination and axonal destruction ultimately leading to chronic inflammation. It is not clear why only a small percentage of HTLV-1infected individuals develop these diseases. Also, the sequence and' nature of events that contribute to ATL and HAM/TSP are not completely understood and this is the reason why clinical management of both these diseases has been unsatisfactory.

${ }^{1}$ Department of Microbiology and Immunology, and the Drexel Institute for Biotechnology and Virology, Drexel University College of Medicine, Philadelphia, Pennsylvania.

${ }^{2}$ National Cancer Institute, Division of Cancer Epidemiology and Genetics, Bethesda, Maryland.

${ }^{3}$ Department of Microbiology and Immunology, University of Pennsylvania School of Medicine, Philadelphia, Pennsylvania. 
Activation of naive $\mathrm{T}$ cells requires the formation of close physical contact (termed as immunological synapse) between a T cell and an antigen-presenting cell (APC). APCs provide two kinds of signals: signal one (antigen presentation) and signal two (costimulation). All types of APCs can provide signal one, but only professional APCs, with dendritic cells (DCs) being the most potent type, can provide both signals. Therefore, DCs play a crucial role in initiating and regulating a potent antiviral $\mathrm{T}$ cell response and many viruses are known to modulate DC functions in order to cause productive infection within their host. With respect to their role in HTLV-1 immunopathogenesis, DCs from HAM/TSP patients were found to be infected with HTLV-1 and capable of stimulating autologous lymphocyte proliferation. ${ }^{4} \mathrm{We}^{5,6}$ and others ${ }^{7}$ have also demonstrated that DCs can become infected with HTLV-1 in vitro. Following exposure to HTLV-1 and Tax, the murine as well as human DCs undergo activation and maturation, exhibiting changes in activation markers, surface phenotype, and secretion of cytokines/chemokines leading to allogeneic and Tax-specific immune responses. ${ }^{8-12}$ Moreover, both Tax protein and its epitope ${ }^{11-19}$ were found to be potent enough to drive an efficient DC-dependent antigenspecific cytotoxic T lymphocyte (CTL) response in naive peripheral blood lymphocytes from the normal donor as well as in HLA-A2.1 transgenic mice ${ }^{6}$ (unpublished observations). In parallel studies on CD11c-DTR mice, we showed that DC priming in early stages of HTLV-1 infection could have an important role in subsequent disease progression. ${ }^{13}$

These studies place DCs in the forefront of HTLV-1 pathogenesis and warrant the need to better understand how DC responses differ in carriers versus diseased individuals, ATL, or HAM/TSP. ${ }^{6,7,13,18}$ However, ex vivo phenotypic characterization and functional characterization of DCs pose a problem due to the low frequency of these cells in the peripheral blood $(0.4 \%$ and $0.2 \%$ for $\mathrm{mDCs}$ and $\mathrm{pDCs}$, respectively) and the multiple markers needed to identify specific DC subsets. Polychromatic flow cytometry is a useful technique for circumventing this problem that offers high sensitivity and greater statistical power. Few reports have demonstrated the use of polychromatic flow cytometry for the characterization of DCs in both blood and peripheral blood mononuclear cells (PBMCs). ${ }^{14-16}$ While useful, these assays present some limitations including lack of phenotypic/ functional characterization and/or inclusion of cumbersome multistep staining with unconjugated and secondary antibodies. Thus, the need still exists for more detailed functional phenotyping of circulating human DC subsets. In this respect, we have developed and standardized a human DC 13color flow cytometry antibody cocktail to perform extensive DC phenotyping within the context of total PBMCs. Once optimized, we used this cocktail to characterize mDCs and pDCs among asymptomatic carriers (ACs), ATL, and HAM/ TSP individuals in a patient cohort from the endemic region of Jamaica. Besides frequencies, we have also focused on markers of maturation, costimulation, and programmed death ligand 1 (PD-L1), which together with its receptor PD-1 has been implicated in $\mathrm{T}$ cell exhaustion during chronic viral infections. ${ }^{17-24}$ Collectively, the results of this study shed light on the role of DCs in the immunopathogenesis of HTLV-1 and serve as a foundation for future comparative analyses of DCs in other patient cohorts from diverse endemic regions.

\section{Materials and Methods}

\section{Clinical samples}

A total of 68 samples (PBMCs) from Jamaica were obtained through collaboration with the National Cancer Institute (Dr. James Goedert, Bethesda, MD) and processed under the institutional review board guidelines. Samples were blinded throughout the study and for the purpose of statistical analyses categorized as Control, ACs, ATL, or HAM/TSP. Detailed subject information can be found elsewhere. ${ }^{25}$ Briefly, each group has 17 individuals including 11 females and 6 males except for the HAM/TSP group, which has 10 females and 7 males. The median age \pm range of females/males was $46 \pm 49 / 38 \pm 45$ (Control), 42 $\pm 43 / 37.5 \pm 60$ (ACs), 49 $\pm 48 /$ $38 \pm 53$ (ATL), and 48 $\pm 45 / 46 \pm 59$ (HAM/TSP). Being from the Jamaican region, the majority of the subjects were of African descent.

\section{Isolation and cryopreservation of PBMCs from seronegative controls}

Buffy coats from six seronegative healthy donors were purchased from Biological Specialty Corp., Colmar, PA, and used for isolation of PBMCs as described previously. ${ }^{10}$ Briefly, PBMCs were isolated using Ficoll-Paque (GE Healthcare, Piscataway, NJ) density gradient centrifugation. Upon isolation, they were first washed twice in HBSS and then suspended in freezing media [ $90 \%$ heat-inactivated fetal bovine serum (FBS) and 10\% dimethyl sulfoxide (DMSO)] followed by cryopreservation in liquid nitrogen for later use.

\section{Antibodies and dyes used for immunostaining}

Figure 1A summarizes all antibodies along with their source, conjugated fluorochrome, isotype, function, and clone. Briefly, the amine-reactive dye, aqua blue, was used to exclude the dead cells from analysis. Lineage cocktail lin-1 [containing FITC-conjugated anti-CD3, anti-CD14, antiCD16, anti-CD19, anti-CD20, and anti-CD56 monoclonal antibodies (mAbs)] was used to gate on the lin-1 ${ }^{-}$DC population. Anti-CD11c and anti-CD123 mAbs were used to gate on specific DC subsets. Other mAbs were used specifically to measure the expression of various costimulation, maturation, activation, and adhesion markers on DCs.

\section{Immunostaining}

Frozen PBMCs were suspended in complete media (RPMI containing $2 \mathrm{mM}$ L-glutamine supplemented with 10\% heat inactivated FBS and 1\% penicillin/streptomycin) and incubated at $37^{\circ} \mathrm{C}$ for $2 \mathrm{~h}$ to recover from cryopreservation. After $2 \mathrm{~h}, \mathrm{PBMCs}$ were suspended in $100 \mu \mathrm{l}$ of FACS staining buffer (DPBS containing 2\% heat-inactivated FBS and $0.09 \%$ sodium azide). All the Abs (including aqua blue dye) were combined into a cocktail and added to PBMCs followed by incubation in the dark at $4^{\circ} \mathrm{C}$ for $45 \mathrm{~min}$. After incubation, cells were washed in DPBS and then fixed with $1 \%$ paraformaldehyde in phosphate-buffered saline (PBS) and stored at $4^{\circ} \mathrm{C}$ in the dark for further processing (analyzed on a flow cytometer within 3 days).

\section{Immunoprofiling of DCs}

Expression of DC markers was measured by flow cytometry using the BD LSR II. 8xRainbow beads (Spherotech Inc., 
FIG. 1. (A) Composition of antibody cocktail. Table 1 lists the clone, isotype, source, and function of each of the antibodies (amine reactive dye is not an antibody) used in the cocktail. (B) Gating strategy for dendritic cells (DCs). The first step is to use a forward scatter (FSC)-A vs. side scatter (SSC)-A ${ }^{44}$ plot to exclude the cellular debris. This is followed by using an FSH-H vs. an FSH-A plot to gate on singlet events. The third step is to exclude dead cells (the cells that stain bright for amine reactive dye). Finally, lin- $1^{-}$cells (DCs) are gated out and further categorized as myeloid dendritic cells (mDCs) or plasmacytoid dendritic cells (pDCs) on the basis of CD11c and CD123 staining.

\begin{tabular}{|c|c|c|c|c|c|}
\hline Fluorochrome & Marker & Clone & Isotype & Function & Source \\
\hline PE-cy5.5 & CD11c & BU15 & Mouse IgG1 & Gating/lineage marker & Invitrogen \\
\hline PerCP-Cy5.5 & CD123 & $6 \mathrm{H} 6$ & Mouse IgG1 & Gating/lineage marker & Biolegend \\
\hline FITC & Lin-1 & \begin{tabular}{|c|} 
3G8, L27, \\
M $\varphi \mathrm{P} 9$, \\
NCAM16.2 \\
,SJ25C1, \\
\end{tabular} & $\begin{array}{c}\text { Mouse IgG2b } \\
\text { and Mouse } \\
\text { IgG1 }\end{array}$ & Gating/lineage marker & $\begin{array}{c}\text { BD } \\
\text { Biosciences }\end{array}$ \\
\hline Aqua Blue & Dead cells & N/A & N/A & Live/dead exclusion & Invitrogen \\
\hline Alexa Fluor 700 & CD54 & $1 \mathrm{H} 4$ & Mouse IgG2b & Cell adhesion & Exbio \\
\hline ECD (PE-TR) & CD62L & DREG56 & Mouse IgG1 & Cell adhesion & $\begin{array}{l}\text { Beckman } \\
\text { Coulter }\end{array}$ \\
\hline PE-Cy5 & CD80 & 2D10.4 & Mouse IgG1 & Co-stimulation & eBioscience \\
\hline $\mathrm{APC}$ & CD86 & 2331 & Mouse IgG1 & Maturation marker & $\mathrm{BD}$ \\
\hline APC-Cy7 & CCR5 & 2D7/CCR5 & Mouse IgG2a & \begin{tabular}{|c|} 
Inflammatory chemokine \\
receptor
\end{tabular} & BD \\
\hline PE & CCR7 & 3D12 & Rat IgG2a & \begin{tabular}{|c|}
$\begin{array}{c}\text { Lymphoid tissue homing } \\
\text { receptor }\end{array}$ \\
\end{tabular} & BD \\
\hline Pacific Blue & HLA-ABC & W6/32 & Mouse IgG2a & Class I MHC & Biolegend \\
\hline Qulot 605 & HLA-DR & Tu36 & Mouse IgG2b & $\begin{array}{c}\text { Class II MHC, Ag } \\
\text { presentation }\end{array}$ & Invitrogen \\
\hline PE-Cy7 & PD-L1 & MIH1 & Mouse IgG1 & Inhibits T-cell activation & Biolegend \\
\hline
\end{tabular}

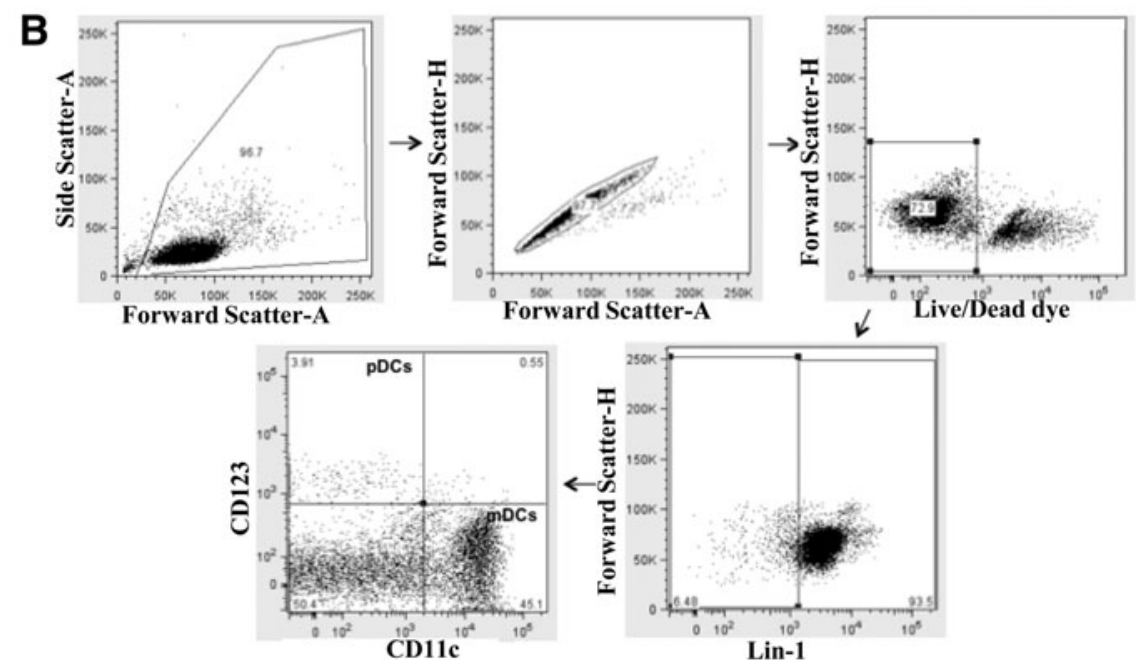

Lake Forest, IL) were used to adjust the detector voltages. Fluorescence compensation was performed using compensation beads (BD, San Jose, CA). Gates for each parameter were determined using fluorescence-minus-one gating (FMO) controls. $^{26,27}$ Five hundred thousand to one million events were acquired per sample for analysis.

\section{Statistical analyses and data interpretation}

The initial data analysis was performed using FlowJo version 8.8.7 software (Tree Star, Ashland, OR). For statistical comparisons between the frequency of DC subsets as well as the geometric mean fluorescence intensity (GMFI) of costimulatory/maturation markers, a two-tailed unpaired $t$-test for nonparametric data (Mann-Whitney) was used. The comparison was determined to be significant $\left.{ }^{*}\right)$ if the $p$ value was $\leq 0.05$, very significant $\left({ }^{* *}\right)$ if $\leq 0.01$, and extremely significant $(* * *)$ if $\leq 0.001$. Statistical calculations were done using the
Prism version 4c software (Graphpad Software Inc., La Jolla, CA). Other data were created either using Microsoft Excel or Simplified Presentation of Complex evaluations (SPICE) software version 4.3 , obtained from Mario Roederer, NIH. ${ }^{28}$

\section{Results}

\section{Optimization of the DC antibody cocktail}

Flow cytometric analysis of cells using a polychromatic antibody cocktail requires an accurate optimization of multiple parameters such as antibody concentrations, type of fluorochromes conjugated, and the combination of fluorochromes. In our cocktail (Fig. 1A), we chose fluorochromes that were biologically inert, had high cell-associated fluorescence intensity, and exhibited little spectral overlap among each other. Compensation was performed (after signal detection but before logarithmic conversion and/or digitization) to eliminate the spectral overlap between different 
fluorochromes. Defining the boundary between positively and negatively stained cells is the most important step in the determination of particular subset of cells as well as functional markers expressed on their surface. For this purpose, we used FMO controls to identify the maximum fluorescence in a given channel when the fluorochrome used in that channel is omitted from the staining panel. This helped us eliminate the nonspecific background staining for each of the fluorochromes. After developing the cocktail, we first tested it on freshly isolated human PBMCs isolated in house from normal donors. The gating strategy used for delineating two DC subsets (mDCs and $\mathrm{pDCs}$ ) and various functional markers expressed on their surface is outlined in Fig. 1A. The first step is to use a forward scatter (FSC)-A vs. side scatter (SSC)- $\mathrm{A}^{29}$ plot to exclude the cellular debris. This is followed by using an FSH-H vs. FSH-A plot to gate on singlet events. The third step is to exclude dead cells (the cells that stain bright for amine reactive dye) by gating on the live cell population (i.e., those staining dimly for Aqua Blue dye). Finally, lin-1- ${ }^{-}$cells (DCs) are selected that are further categorized as mDCs or pDCs on the basis of CD11c and CD123 staining.

\section{Suitability of cocktail for flow cytometric analyses of DCs within frozen PBMCs}

Freshly isolated cells and/or tissue are usually the material of choice for clinical investigations; however, in certain cases, such as the investigation of rare diseases that are endemic in few geographic locations or studying unique patient populations, obtaining freshly isolated samples is not logistically possible and therefore most of them are available in a cryopreserved state. Thus it is important to evaluate the stability of cell surface markers following cryopreservation or short-term culturing since some cell types may be significantly affected by freeze/thaw cycles. Therefore, we used our Ab cocktail to compare the expression of various surface markers among freshly isolated, frozen, and cultured PBMCs. Prior to carrying out this pilot study, we examined cryopreserved PBMCs for the percentage of viable cells, morphology, phenotype of DCs and T cells, and response to concanavalin A (Con A, a mitogen widely used as a control stimulus for T cells) and Tax. Results (compiled in Supplementary Table S1; Supplementary Data are available online at www.liebertpub.com/aid) demonstrate that the frequency of DCs was in the expected range and the phenotype of both DCs and T cells was normal. Also, the $\mathrm{T}$ cells gave a positive response to Con $\mathrm{A}$ and a negative response to Tax (which is expected since these donors are seronegative for HTLV-1).

Once we ensured that cryopreserved PBMCs were functional and therefore suitable for flow cytometric analysis, we obtained a fresh set of six control donors for studying the differences in expression of each individual marker upon freezing and short-term culturing of cells. Figure 2A and B shows the expression of each surface marker for $\mathrm{mDC}$ and pDCs, respectively (data plotted are representative of six donors). The histograms corresponding to fresh, cultured, and frozen PBMCs were overlaid to show changes in expression of a particular marker upon freezing or culturing of PBMCs. No apparent shifts were observed for any marker on both mDCs and pDCs. However, both these populations are rare and the absolute counts of these populations may affect the observed results. Therefore, we normalized our data according to the number of cells acquired on the flow cytometer. Following normalization, we found a slight increase in expression of most of the markers when comparing both frozen and cultured PBMCs to fresh PBMCs. This trend can be more readily seen in Table 1, which summarizes the median values of the normalized GMFIs for both mDCs and pDCs. We then compared GMFI values of each marker between the three groups (fresh, frozen, and cultured). Figure 3 shows the markers that indicated significant differences between any two groups for at least one DC subset. In mDCs, the GMFI of CCR5 and CD54 is significantly higher in frozen compared to freshly isolated cells whereas the GMFI of HLA-DR is significantly higher in cultured compared to freshly isolated cells. pDCs on the other hand do not show statistically significant differences in GMFI of any marker among all three groups. These observations imply that the expression of CD54, CCR5, and HLA-DR can change upon cryopreservation or culturing of $\mathrm{mDC}$ and, therefore, it is important that freshly isolated mDCs from one patient cohort are not compared with frozen mDCs (for characterizing CCR5 and CD54 expression) or cultured mDCs (for HLA-DR expression) from another cohort.

\section{Frequency of $m D C s$ and $p D C s$ \\ in HTLV-1-infected individuals}

After optimizing and validating the Ab cocktail, we carried out immunoprofiling of frozen PBMCs of HTLV-1-infected individuals (both ACs and individuals with HTLV-1-associated diseases, ATL, and HAM/TSP. Before investigating the differences in the phenotypic and functional state of two major DC subsets, mDCs and pDCs, across all the groups, we first wanted to compare their frequency across the groups. Our results demonstrate that compared to controls (but not ACs), HAM/ TSP individuals have a significantly higher frequency of $\mathrm{mDCs}$ ( $p=0.04$, Fig. 4A). The frequencies of mDCs in controls, ACs, and ATL individuals are comparable. However, both ATL and HAM/TSP individuals have significantly lower frequencies of pDCs (Fig. 4B) compared to controls ( $p=0.02$ and 0.0008, respectively) and ACs ( $p=0.01$ and 0.001 , respectively).

\section{DCs from HAM/TSP and ATL individuals are phenotypically different from ACs}

CD80 and CD86 expressed on DCs are responsible for providing costimulatory signals necessary for T cell activation and survival. On other hand, HLA-ABC (MHC Class I molecule) and HLA-DR (MHC Class II molecule) play a crucial role in antigen presentation. Thus, these four proteins are important markers of immune activation during viral infection and therefore we investigated their expression in all four groups (controls, ACs, ATL, and HAM/TSP individuals). In mDCs, CD80 and CD86 expression did not vary significantly between controls and each of the remaining three groups (Fig. 5). There was no significant difference in CD80 and CD86 expression between the ACs and ATL group, but the HAM/ TSP group had significant upregulation of both these markers compared to ACs ( $p=0.03$ for both CD80 and CD86). Similar to CD80 and CD86, HLA-ABC and HLA-DR expression did not vary significantly between controls and other groups. However; HLA-ABC was significantly higher in the ATL group compared to ACs $(p=0.01)$ and HLA-DR was significantly lower in the HAM/TSP group compared to ACs 
FIG. 2. Characterizing the expression of DC markers on fresh, frozen, and cultured peripheral blood mononuclear cells (PBMCs) in healthy donors. The analysis for one representative sample out of six healthy samples is shown. (A) From the gated $\mathrm{mDC}$ population, the expression of each phenotypic marker was analyzed by plotting histograms of fresh, cultured, and frozen cells of the same donor. The bars indicate the positive gates. (B) The same peaks described in (A) were created from the gated $\mathrm{pDC}$ population.
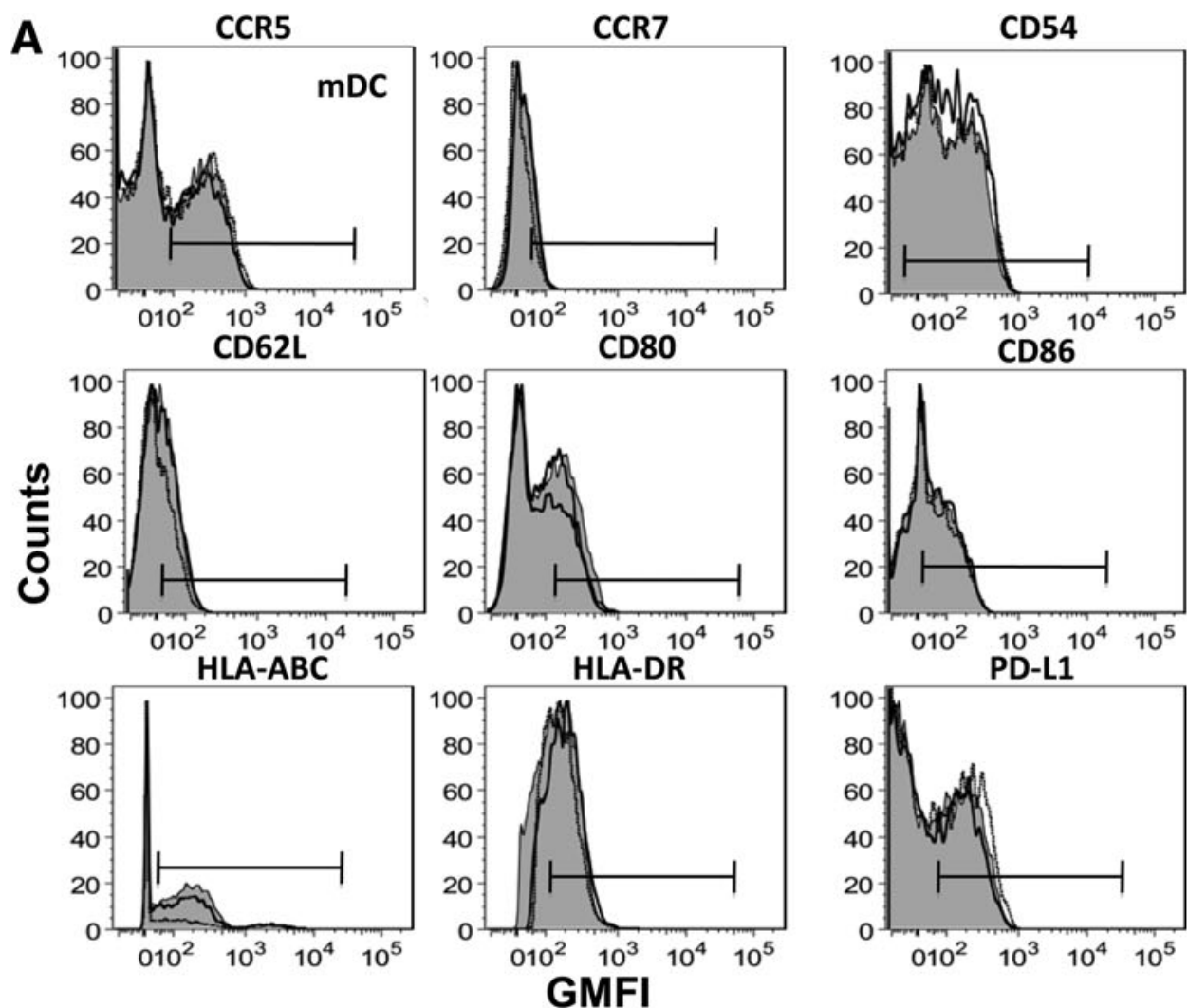

B

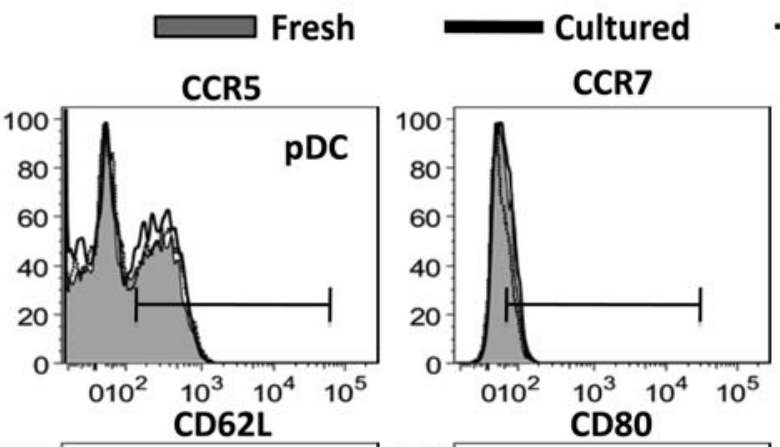

Frozen
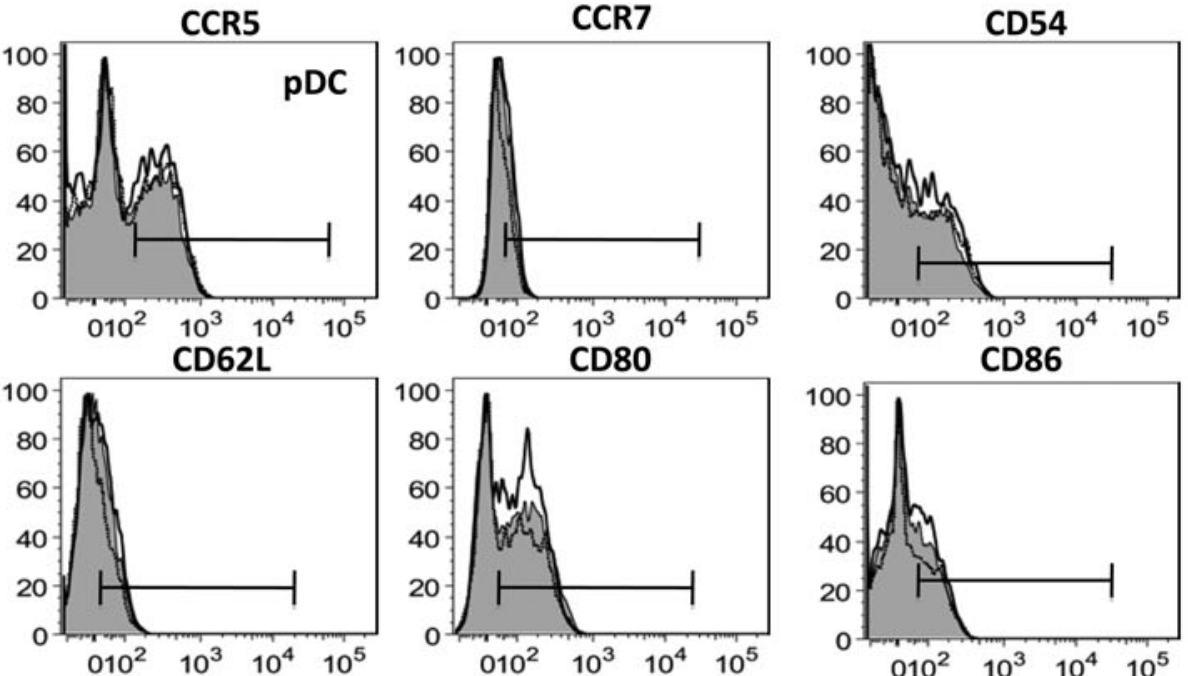

HLA-ABC
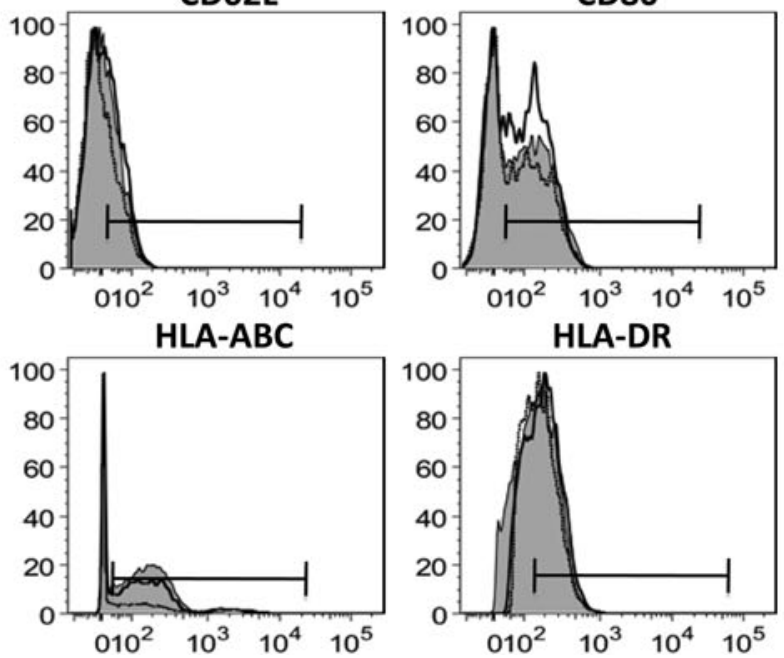

HLA-DR

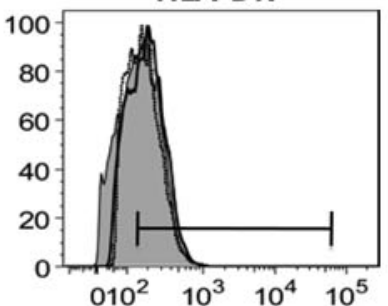

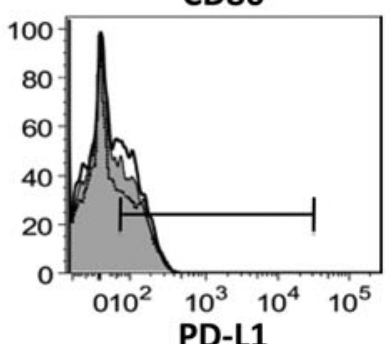

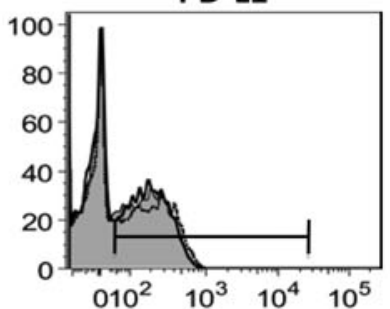


Table 1. Median Geometric Mean Fluorescence Intensity Values for Various Surface Markers on Myeloid Dendritic Cells and Plasmacytoid Dendritic Cells

\begin{tabular}{|c|c|c|c|c|c|c|}
\hline \multirow[b]{2}{*}{ Markers } & \multicolumn{3}{|c|}{ Median $G M F I \pm S D(m D C)$} & \multicolumn{3}{|c|}{ Median GMFI $\pm S D(p D C)$} \\
\hline & Fresh & Cultured & Frozen & Fresh & Cultured & Frozen \\
\hline CCR5 & $128 \pm 72$ & $260 \pm 328$ & $221 \pm 59$ & $102 \pm 82$ & $179 \pm 133$ & $220 \pm 192$ \\
\hline CCR7 & $50 \pm 207$ & $155 \pm 93$ & $102 \pm 76$ & $58 \pm 119$ & $99 \pm 73$ & $135 \pm 274$ \\
\hline CD54 & $103 \pm 59$ & $211 \pm 141$ & $180 \pm 44$ & $72 \pm 57$ & $104 \pm 123$ & $117 \pm 100$ \\
\hline CD62L & $66 \pm 328$ & $163 \pm 149$ & $113 \pm 83$ & $50 \pm 194$ & $65 \pm 342$ & $73 \pm 282$ \\
\hline CD80 & $62 \pm 60$ & $149 \pm 135$ & $116 \pm 62$ & $65 \pm 77$ & $94 \pm 89$ & $126 \pm 129$ \\
\hline CD86 & $56 \pm 67$ & $113 \pm 59$ & $88 \pm 68$ & $65 \pm 54$ & $67 \pm 67$ & $107 \pm 204$ \\
\hline HLA-ABC & $1006 \pm 6016$ & $1377 \pm 2534$ & $1024 \pm 2740$ & $647 \pm 6795$ & $441 \pm 2431$ & $871 \pm 3828$ \\
\hline HLA-DR & $94 \pm 122$ & $293 \pm 142$ & $142 \pm 79$ & $90 \pm 224$ & $288 \pm 166$ & $140 \pm 353$ \\
\hline PD-L1 & $78 \pm 39$ & $147 \pm 216$ & $155 \pm 144$ & $57 \pm 68$ & $132 \pm 78$ & $143 \pm 33$ \\
\hline
\end{tabular}

GMFI, geometric mean fluorescence intensity; mDC, myeloid dendritic cells; pDC, plasmacytoid dendritic cells.
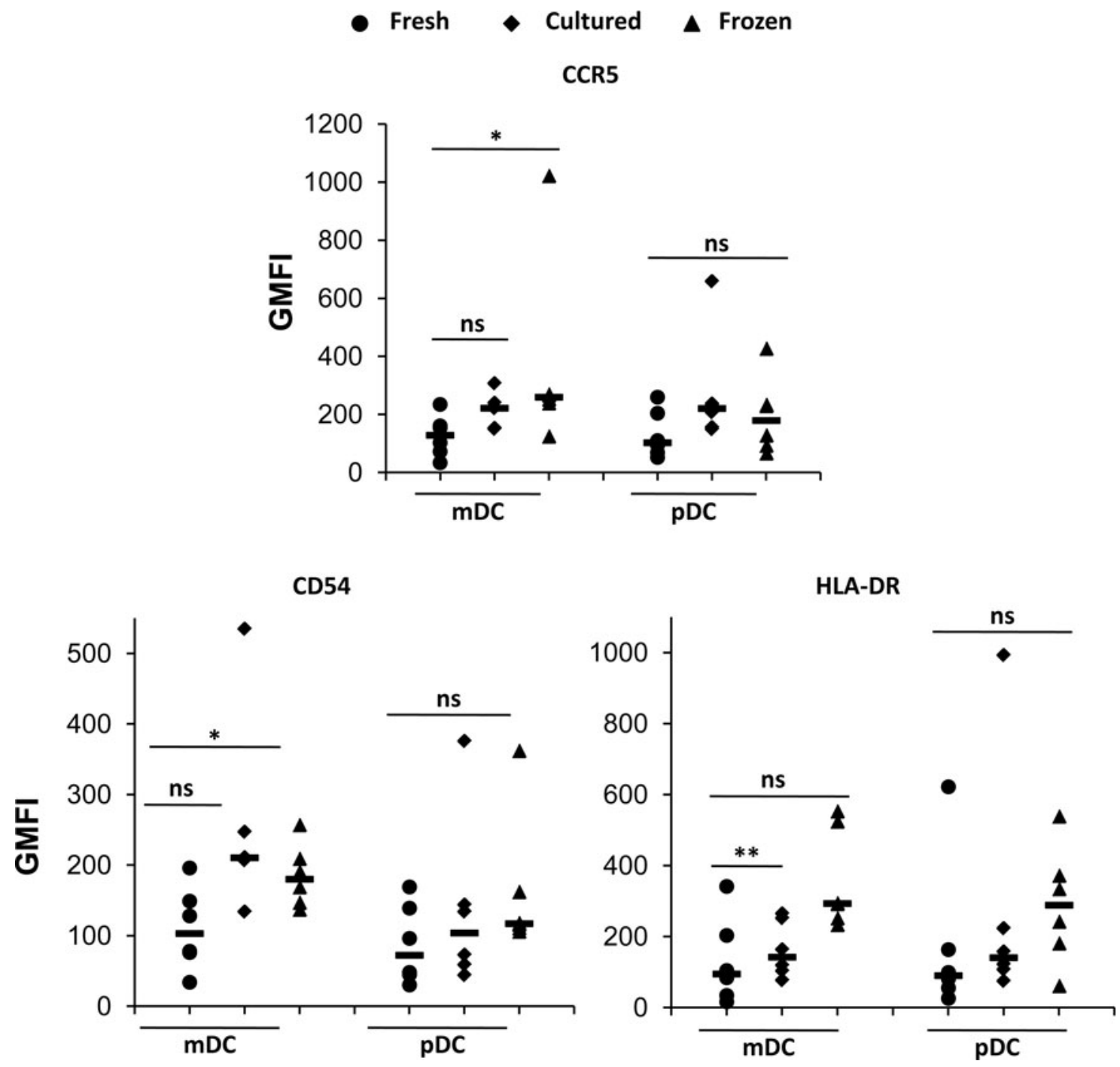

FIG. 3. Scatter plots for selected markers on human mDCs and pDCs. Individual geometric mean fluorescence intensity (GMFI) values of fresh (circle), cultured (diamond), and frozen (triangle) cells were plotted for the selected markers CCR5 (top), CD54 (middle), and HLA-DR (bottom). Horizontal lines represent the median values. $p$ values for statistical comparisons between different groups were calculated using the Mann-Whitney test. ${ }^{*} p \leq 0.05$, ${ }^{* *} p \leq 0.01$, and ns denotes no significant difference. 


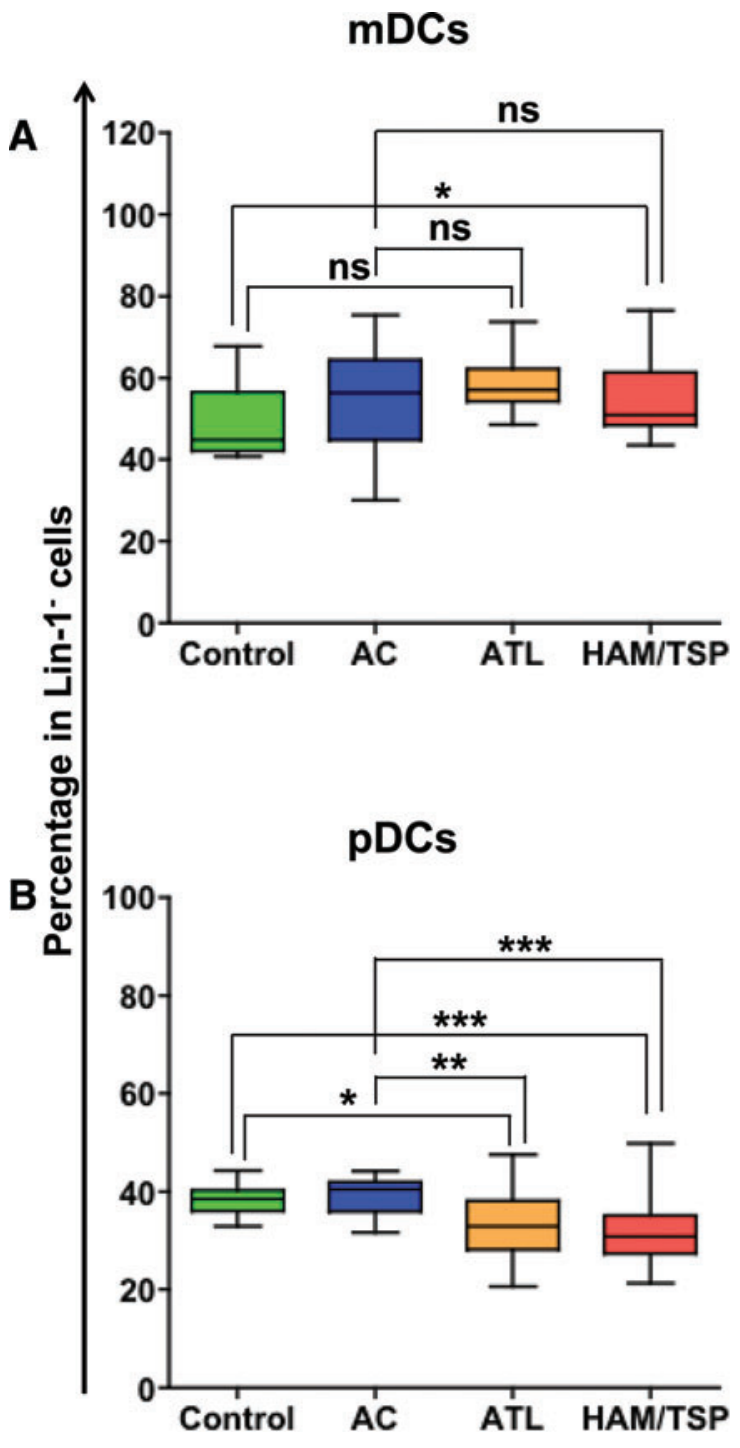

FIG. 4. Percentage of DC subsets among seronegative controls, asymptomatic carriers, adult T cell leukemia (ATL), and HTLV-associated myelopathy/tropical spastic paraparesis (HAM/TSP) individuals. Frequencies of (A) mDCs and (B) pDCs were plotted as the percentage of lin- $1^{-}$cells (box and whiskers graph). $p$ values for statistical comparisons between different groups were calculated using the MannWhitney test. ${ }^{*} p \leq 0.05,{ }^{* *} p \leq 0.01,{ }^{* * *} p \leq 0.001$, and ns denotes no significant difference observed. Color images available online at www.liebertpub.com/aid

$(p=0.05)$. We then made similar comparisons of these markers across all four groups in pDCs as well. The expression of CD80 and HLA-ABC was comparable between all groups. HLA-DR expression was significantly lower in both ATL and HAM/TSP groups compared to ACs $(p=0.03$ and 0.02 respectively) whereas CD86 expression was significantly higher in HAM/TSP (but not the ATL group) compared to ACs.

\section{ACs coexpress more adhesion molecules} than ACs or ATLS

CD54 and CD62L (adhesion molecules) and CCR5 and CCR7 (chemokine receptors) play a critical role in the mi- gration of immune cells including DCs to lymph nodes. These four proteins are regarded as important markers of DC activation and hence their ability to stimulate a $\mathrm{T}$ cell response during chronic viral infections. We therefore evaluated the simultaneous expression of two or more of these markers in all four groups. We used a data presentation tool, Simplified Presentation of Incredibly Complex Evaluations (SPICE), that is commonly used to depict the polyfunctionality profiles of cells in which each slice of the pie represents the number of markers that these cells express and the arcs above each pie are used to separately represent the expression of every molecule among a given number of coexpressed markers. Our data show that all four groups had similar percentages of DCs (both mDCs and pDCs) that coexpress all four markers. Compared to ACs, the ATL and HAM/TSP group had a lower percentage of DCs that coexpressed two or three markers. CD54 and CD62L were two markers that were expressed at higher levels in ACs compared to the ATL and HAM/TSP group (Fig. 6)

\section{HAM/TSP individuals have enhanced expression of $P D-L 1$}

Another marker of interest in the cocktail was PD-L1. PDL1 is found on resting T cells, B cells, macrophages, and DCs and binds to its receptor PD-1, which is an inhibitory receptor found on the surface of activated T cells. The PD-1: PD-L1 signaling pathway is a negative regulatory pathway that results in T cell exhaustion that is characteristic of many chronic viral infections. ${ }^{17-24}$ Therefore, we investigated the expression of PD-L1 on both mDCs and pDCs in all four groups (Fig. 7). Our results show that the expression of PD-L1 did not vary significantly between ATL individuals and both controls and ACs. On other hand, mDCs of HAM/TSP individuals have a significantly higher expression of PD-L1 compared to controls $(p=0.004)$ and ACs $(p=0.04)$. Also, pDCs of HAM/TSP individuals demonstrated a significantly higher PD-L1 expression compared to controls $(p=0.005)$.

\section{Discussion}

DCs play a central role in initiating antigen-specific immunity. Many chronic viral infections are known to interfere with DCs functions; therefore it is extremely important to characterize their phenotypic and functional state during a particular pathological state not only to develop an understanding of disease pathophysiology but also to design better treatment strategies. It is often difficult to obtain fresh blood from individuals with a certain microbial infection because the infection is not endemic to the location of study. Thus, most of the samples are shipped in a cryopreserved state and therefore it becomes necessary to confirm that there are no artifacts due to freezing of cells.

DCs require multiple markers for their phenotyping. In this respect, Wang et al. ${ }^{16}$ developed an 11-color polychromatic antibody cocktail to detect human $\mathrm{pDC}, \mathrm{mDC} 1$, and $\mathrm{mDC} 2$ subsets within PBMCs. The markers used in this particular study include many gating markers, but few functional markers. Fung et al. ${ }^{15}$ have developed two 8-color polychromatic antibody cocktails for the characterization of circulating human DCs, monocytes, and B lymphocytes. These assays included markers for chemotaxis, adhesion, Ag presentation, and immune regulation. A 12-color panel was developed to 


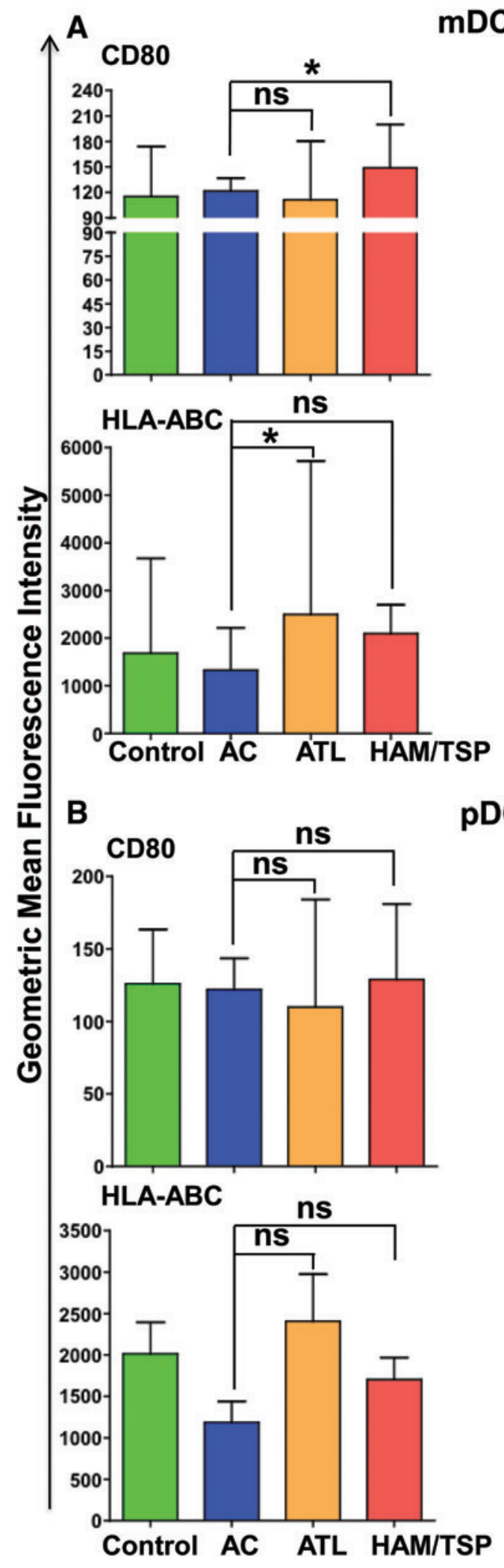

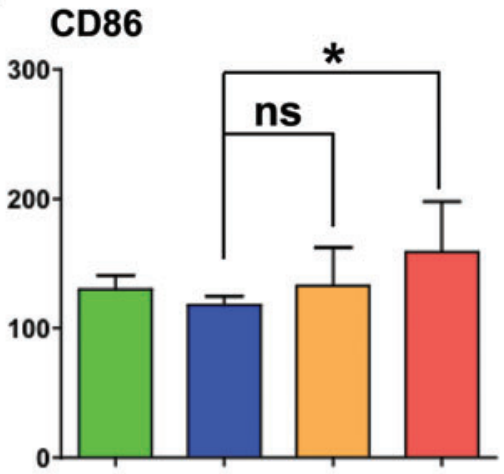

HLA-DR

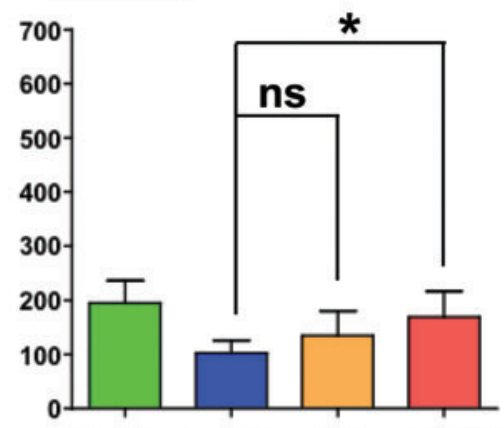

Control AC ATL HAM/TSP

pDCs
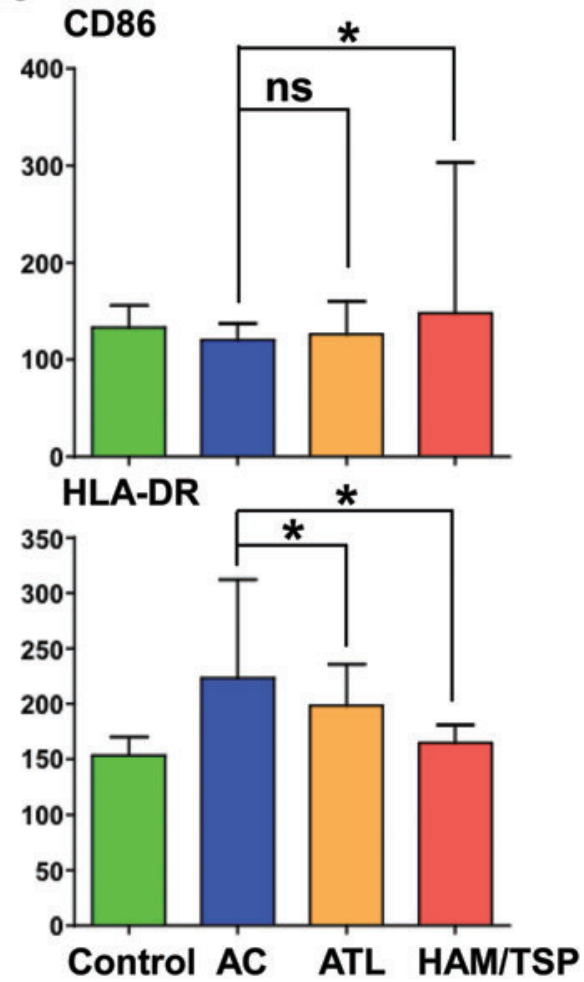

FIG. 5. Comparison of GMFI of costimulatory/maturation markers. Median GMFI values of CD80, CD86, CCR5, and CCR7 along with standard deviations were plotted for (A) mDCs and (B) pDCs. $p$ values for statistical comparisons between different groups were calculated using the MannWhitney test. ${ }^{*} p \leq 0.05$ and ns denotes no significant difference observed. Color images available online at www .liebertpub.com/aid 


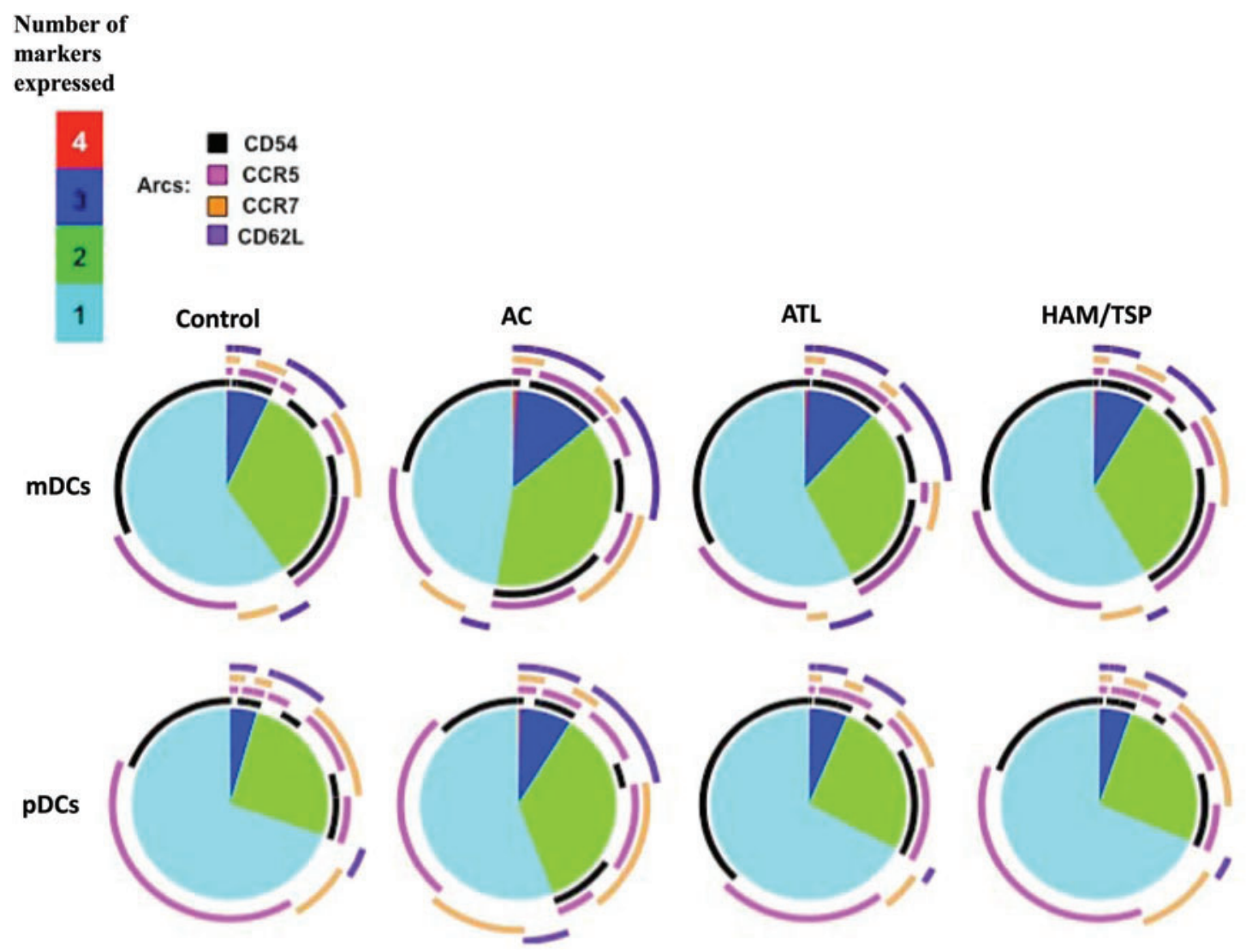

FIG. 6. Asymptomatic carriers (ACs) coexpress more adhesion molecules than the ATL and HAM/TSP groups. Data depict the average coexpression among all the donors stratified by cell type (i.e., mDC or pDC) and patient category. Controls $n=13$, ACs $n=12$, ATL, $n=17$, and HAM/TSP $n=15$. Pie slices represent the proportions of DCs that coexpress all four, three, two, or one adhesion molecule. Within each of these slices, arcs represent the portion of the specific markers expressed in those populations. Color images available online at www.liebertpub.com/aid

simultaneously detect human lymphocytes, monocytes, and all known DC subsets. ${ }^{14}$ The markers included in this cocktail were strictly for the purpose of gating but not functional characterization. Although useful, these assays still have some limitations, including lack of enough phenotypic/ functional characterization and/or inclusion of cumbersome multistep staining with unconjugated and secondary antibodies. Thus, there is a need for the comprehensive characterization of phenotypic and functional markers of peripheral blood DCs. Our antibody cocktail overcomes these limitations and is thus a very useful tool for immunophenotyping DCs in individuals with chronic viral infections. We have also tested this cocktail on fresh, frozen, and cultured PBMCs to ascertain the changes in expression of markers as a result of freezing or short-term culturing.

Subsequently, we utilized the newly developed cocktail to investigate the frequency as well as the quality of DCs in HTLV-1-infected individuals (both ACs and diseased individuals) in order to understand their role in disease progression. Our results showed that compared to controls (but not ACs), HAM/TSP individuals have significantly higher frequency of mDCs (Fig. 4A), which is contrary to another study performed on a patient cohort from Japan. ${ }^{30}$ This could be due to inherent differences in the patient population and/ or the processing of samples for the ex vivo analyses. It is important to note that the higher frequency of mDCs in
HAM/TSP individuals could potentially be due to impairment of their ability to migrate to lymph nodes because of reduced expression of adhesion molecules and chemokine receptors.

With respect to pDCs, both ATL and HAM/TSP individuals showed significantly lower frequencies of these cells compared to controls and ACs (Fig. 4B), a finding similar to other studies. ${ }^{30-32}$ The reduced frequency of pDCs observed in diseased individuals could be due to HTLV-induced apoptosis or redistribution to lymphoid tissues as reported for $\mathrm{HIV} / \mathrm{SIV} .{ }^{33,34}$ pDCs have also been reported to accumulate in the lymphoid tissues, including spleen, of individuals with chronic HIV infection. ${ }^{35,36}$ It is not clear if this holds true for HTLV-1, but since HTLV-1 is known to infect pDCs, ${ }^{5,7}$ it will be interesting to study whether HTLV-1 infection can induce the apoptosis/redistribution of pDCs. Since pDCs are the major producers of type I interferons (IFNs), it is possible that the virus causes their depletion in order to cause productive infection in the host.

pDCs express high amounts of BDCA-4 known to be involved in HTLV-1 entry; however, little is known about whether HTLV-1 can trigger innate immune responses in pDCs. Colisson et al. ${ }^{37}$ have shown that cell-free HTLV-1 can induce toll-like receptor 7 (TLR7)-dependant IFN production as well as upregulation of costimulatory markers CD40, CD83, and CD86 in pDCs. Additionally, it was shown that 
A

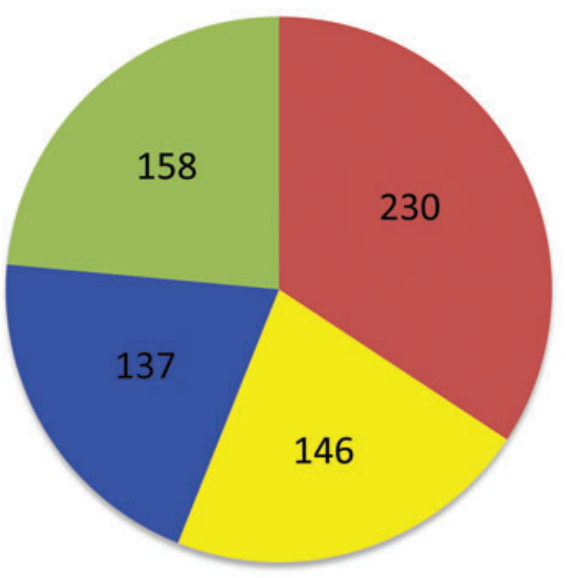

Median GMFI values (mDCs)
PD-L1

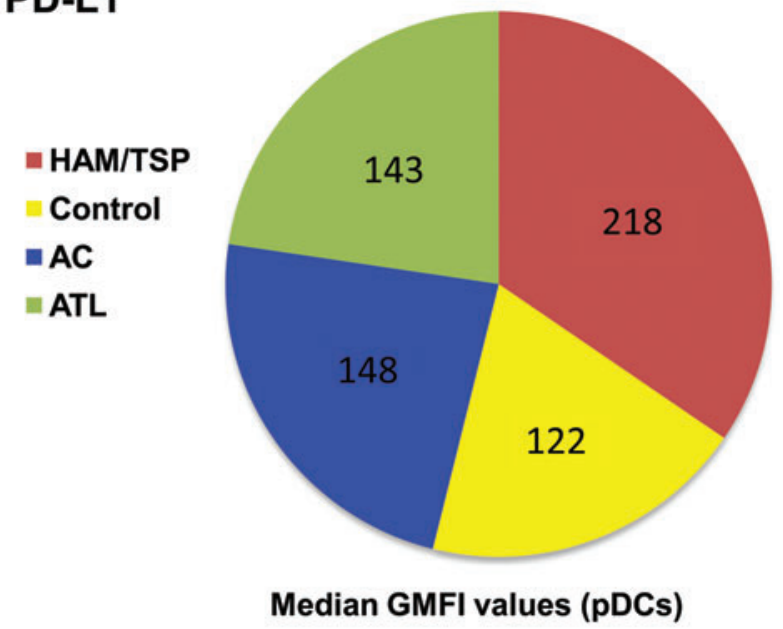

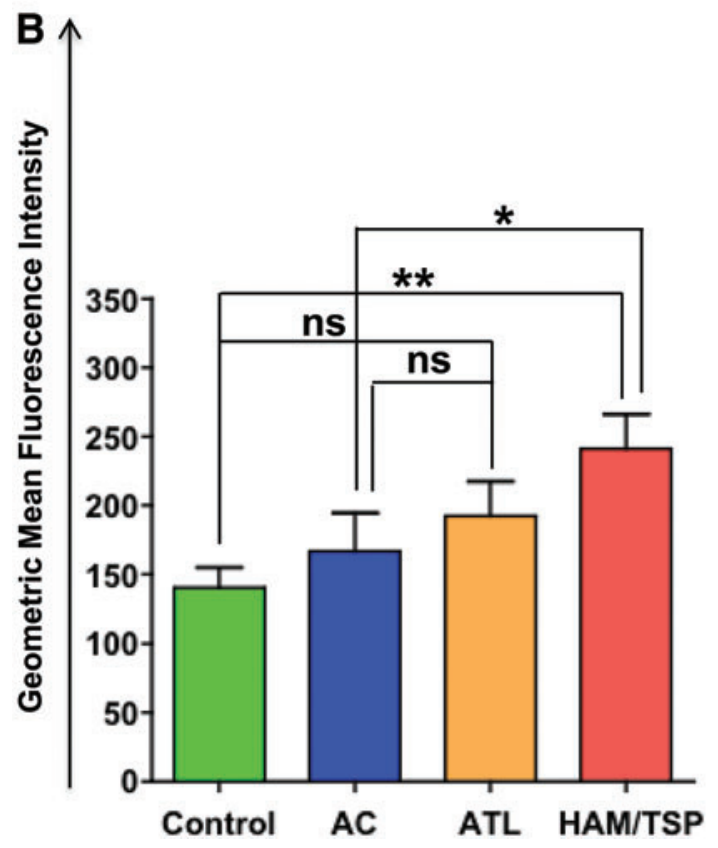

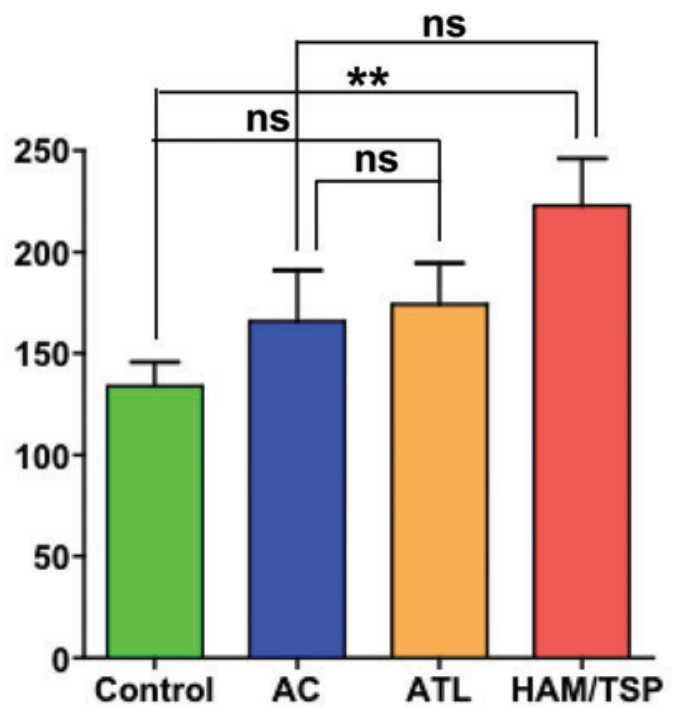

FIG. 7. Comparison of median GMFI values of programmed death ligand 1 (PD-L1). Median GMFI values for PD-L1 were compared among each sample category and plotted as (A) pie chart and (B) bar graphs representing median and standard deviation. $p$ values were calculated using the Mann-Whitney test. ${ }^{*} \leq 0.05,{ }^{* *} p \leq 0.01$. Color images available online at www.liebertpub.com/aid

HTLV-1-activated pDCs rapidly express proapoptotic tumor necrosis factor (TNF)-related apoptosis inducing ligand (TRAIL), thus transforming them into IFN-producing killer pDCs (IKpDC) that are capable of inducing apoptosis in $\mathrm{CD}^{+} \mathrm{T}$ cells expressing DR5 (the receptor for TRAIL). Tax has been shown to inhibit the TRAIL apoptotic pathway in HTLV-1-infected $\mathrm{T}$ cells and therefore it is possible that IKpDCs may lead to the emergence of TRAIL-resistant Taxpositive cells, leading to ATL. In light of these observations, it will be interesting to investigate whether IKpDCs persist during chronic infection and if they do, what impact they have on the proviral load (since $\mathrm{CD} 4^{+} \mathrm{T}$ cells are the major targets of HTLV-1) and disease progression.

It is known that $\mathrm{T}$ cells have an increased expression of adhesion molecules upon HTLV-1 infection, ${ }^{38}$ but not much is known regarding the same in DCs. Our study has shown that the adhesion profile of DCs in ACs is considerably different from the disease groups. Adhesion molecules are necessary for proper DC-T cell contacts and therefore individuals with coexpression of multiple adhesion markers on DCs can prime the $\mathrm{T}$ cells efficiently, consequently improving the quality of the immune response. Our findings on CD86 and HLA-ABC expression are contradictory to another study performed on a Japanese cohort, ${ }^{30}$ which reports that CD86 and HLA-ABC expression on DCs (both mDCs and pDCs) was either negligible or comparable among all the groups. It is important to note that these differences could be due to the fact that subjects in our study were from a different endemic region (Jamaica) and therefore the host genetic factors and disease prevalence (ATL is more common in Japan, whereas HAM/ 
TSP is more common in the Caribbean) could be responsible for the observed differences between these two cohorts. These differences could potentially provide novel insight into HTLV-1 pathogenicity.

The PD-1: PD-L1 signaling pathway is a negative regulatory pathway that results in suppression of $\mathrm{T}$ cell functions. ${ }^{39}$ Chronic infection with lymphocytic choriomeningitis virus (LCMV), HIV, and hepatitis C virus (HCV) is known to result in upregulation of PD-1 expression. ${ }^{20,40,41}$ PD-1 has also been shown to be upregulated on HTLV-1-specific CTLs in $\mathrm{ATL}^{42}$ and HAM/TSP individuals. ${ }^{43}$ Increased PD-1 expression on $\mathrm{CD}^{+} \mathrm{T}$ cells from individuals with Sézary syndrome, a common cutaneous $\mathrm{T}$ cell lymphoma with symptoms similar to ATL, may explain the immunosuppression of this disease. ${ }^{44}$ Furthermore, specifically in ATL the neoplastic T cell population, characterized by a $\mathrm{CD} 4{ }^{+} \mathrm{CD} 25^{+}$phenotype, exhibits increased PD-1 expression with a correlative increase in the absolute number of tumor cells. A correlation between the downregulation of PD-1 expression and the improvement in clinical disease outcome in Sézary syndrome as well as HIV-1 has also been noted. ${ }^{44}$ Since PD-L1 is the ligand for PD-1, it is reasonable to hypothesize that PD-L1 expression would be high in ATL and HAM/TSP individuals. Our study has shown that both mDCs and pDCs of HAM/TSP individuals have significantly higher PD-L1 expression compared to ACs. Although not found to be significant, there was a slight increase of PD-L1 in the $\mathrm{mDC}$ and $\mathrm{pDC}$ populations of the ATL group compared to controls. In separate investigations, a pool of overlapping Tax peptides stimulated a polyfunctional recall response in $\mathrm{CD}^{+} \mathrm{T}$ cells from ACs but failed to do so in ATL and HAM patients. $^{25}$ The observed lack of $\mathrm{T}$ cell polyfunctionality and high proviral loads in patients directly correlated with the increased expression of the PD-1 receptor on T cells implying the exhaustion of HTLV-specific immune response leading to viral persistence and disease progression. PD-L1/PD-1 could thus be a useful prognostic marker for better clinical management of HTLV-1-associated diseases, especially HAM/TSP. In fact, studies on HIV, HBV, and HCV have confirmed that PD-L1/PD-1 blockade can lead to enhanced effector functions of exhausted $\mathrm{CD}^{+} \mathrm{T}$ cells. ${ }^{2,45-51}$ Some groups suggest that blocking PD-L1 may have a higher efficacy in restoring $\mathrm{T}$ cell function compared to targeting PD-1. ${ }^{45}$ Moreover, direct inhibition of PD-1 has been shown to lead to increased inflammatory toxicity, ${ }^{52}$ whereas these adverse effects have not been reported with PD-L1 blocking antibody. ${ }^{53}$

To our knowledge this is the first comprehensive human DC phenotyping study that used an extensive list of functional markers to determine functional differences among DCs from HTLV-1-seronegative controls, ACs, ATL, and HAM/TSP patients. With these data in mind, the future direction should be guided toward the evaluation of possible targets for therapeutic intervention.

\section{Acknowledgments}

This work was supported by the Public Health Service, National Institutes of Health, wherein P.J. was funded through NIAID R01 AI077414 and NCI R01 CA054559 while Z.K.K. was funded through NIAID R21 AI 093172-01. In addition, we thank the Philadelphia NeuroAIDS Training Grant T32 MH079785 that has supported the efforts of S. Manuel.
J.J.G. provided the individuals samples for the study. P.J., M.R.B., and Z.K.K. designed the study and experimental strategies. S.L.M. conducted the experimentation. S.L.M., M.S., and P.J. evaluated and interpreted data, structured the data presentation, and framed and edited the article.

\section{Author Disclosure Statement}

No competing financial interests exist.

\section{References}

1. Goncalves DU, Proietti FA, Ribas JG, et al.: Epidemiology, treatment, and prevention of human T-cell leukemia virus type 1-associated diseases. Clin Microbiol Rev 2010;23(3): 577-589.

2. Proietti FA, Carneiro-Proietti AB, Catalan-Soares BC, and Murphy EL: Global epidemiology of HTLV-I infection and associated diseases. Oncogene 2005;24(39):6058-6068.

3. Sonoda S, Li HC, and Tajima K: Ethnoepidemiology of HTLV-1 related diseases: Ethnic determinants of HTLV-1 susceptibility and its worldwide dispersal. Cancer Sci 2011; 102(2):295-301.

4. Macatonia SE, Cruickshank JK, Rudge P, and Knight SC: Dendritic cells from patients with tropical spastic paraparesis are infected with HTLV-1 and stimulate autologous lymphocyte proliferation. AIDS Res Hum Retroviruses 1992;8(9):1699-1706.

5. Jain P, Manuel SL, Khan ZK, Ahuja J, Quann K, and Wigdahl B: DC-SIGN mediates cell-free infection and transmission of human T-cell lymphotropic virus type 1 by dendritic cells. J Virol 2009;83(21):10908-10921.

6. Manuel SL, Schell TD, Acheampong E, Rahman S, Khan ZK, and Jain P: Presentation of human T cell leukemia virus type 1 (HTLV-1) Tax protein by dendritic cells: The underlying mechanism of HTLV-1-associated neuroinflammatory disease. J Leukoc Biol 2009;86(5):1205-1216.

7. Jones KS, Petrow-Sadowski C, Huang YK, Bertolette DC, and Ruscetti FW: Cell-free HTLV-1 infects dendritic cells leading to transmission and transformation of CD4(+) T cells. Nat Med 2008;14(4):429-436.

8. Ahuja J, Kampani K, Datta S, Wigdahl B, Flaig KE, and Jain $P$ : Use of human antigen presenting cell gene array profiling to examine the effect of human T-cell leukemia virus type 1 Tax on primary human dendritic cells. J Neurovirol 2006; 12(1):47-59.

9. Ahuja J, Lepoutre V, Wigdahl B, Khan ZK, and Jain P: Induction of pro-inflammatory cytokines by human T-cell leukemia virus type-1 Tax protein as determined by multiplexed cytokine protein array analyses of human dendritic cells. Biomed Pharmacother 2007;61(4):201-208.

10. Jain $P$, Ahuja J, Khan $Z K$, et al.: Modulation of dendritic cell maturation and function by the Tax protein of human $\mathrm{T}$ cell leukemia virus type 1. J Leukoc Biol 2007;82(1):44-56.

11. Mostoller K, Norbury CC, Jain P, and Wigdahl B: Human T-cell leukemia virus type I Tax induces the expression of dendritic cell markers associated with maturation and activation. J Neurovirol 2004;10(6):358-371.

12. Rahman S, Khan ZK, Wigdahl B, Jennings SR, Tangy F, and Jain P: Murine FLT3 ligand-derived dendritic cell-mediated early immune responses are critical to controlling cell-free human $\mathrm{T}$ cell leukemia virus type 1 infection. J Immunol 2011;186(1):390-402.

13. Rahman S, Manuel SL, Khan ZK, et al.: Depletion of dendritic cells enhances susceptibility to cell-free infection of human $\mathrm{T}$ 
cell leukemia virus type 1 in CD11c-diphtheria toxin receptor transgenic mice. J Immunol 2010;184(10):5553-5561.

14. Autissier P, Soulas C, Burdo TH, and Williams KC: Evaluation of a 12-color flow cytometry panel to study lymphocyte, monocyte, and dendritic cell subsets in humans. Cytometry A 2010;77(5):410-419.

15. Fung E, Esposito L, Todd JA, and Wicker LS: Multiplexed immunophenotyping of human antigen-presenting cells in whole blood by polychromatic flow cytometry. Nat Protoc 2010;5(2):357-370.

16. Wang JC, Kobie JJ, Zhang L, et al.: An 11-color flow cytometric assay for identifying, phenotyping, and assessing endocytic ability of peripheral blood dendritic cell subsets in a single platform. J Immunol Methods 2009;341(1-2):106-116.

17. Ha SJ, Mueller SN, Wherry EJ, et al.: Enhancing therapeutic vaccination by blocking PD-1-mediated inhibitory signals during chronic infection. J Exp Med 2008;205(3):543-555.

18. Sakthivel P, Gereke M, and Bruder D: Therapeutic intervention in cancer and chronic viral infections: Antibody mediated manipulation of PD-1/PD-L1 interaction. Rev Recent Clin Trials 2012;7(1):10-23.

19. Finnefrock AC, Tang A, Li F, et al.: PD-1 blockade in rhesus macaques: Impact on chronic infection and prophylactic vaccination. J Immunol 2009;182(2):980-987.

20. Freeman GJ, Wherry EJ, Ahmed R, and Sharpe AH: Reinvigorating exhausted HIV-specific T cells via PD-1-PD-1 ligand blockade. J Exp Med 2006;203(10):2223-2227.

21. Dyavar Shetty R, Velu V, Titanji K, et al.: PD-1 blockade during chronic SIV infection reduces hyperimmune activation and microbial translocation in rhesus macaques. J Clin Invest 2012;122(5):1712-1716.

22. Velu V, Titanji K, Zhu B, et al.: Enhancing SIV-specific immunity in vivo by PD-1 blockade. Nature 2009;458(7235): 206-210.

23. Urbani S, Amadei B, Tola D, et al.: Restoration of HCVspecific $\mathrm{T}$ cell functions by PD-1/PD-L1 blockade in HCV infection: Effect of viremia levels and antiviral treatment. J Hepatol 2008;48(4):548-558.

24. Ikebuchi R, Konnai S, Shirai $\mathrm{T}$, et al.: Increase of cells expressing PD-L1 in bovine leukemia virus infection and enhancement of anti-viral immune responses in vitro via PD-L1 blockade. Vet Res 2011;42(1):103-117.

25. Manuel SL, Sehgal M, Connolly J, Makedonas G, Khan ZK, Gardner J, Goedert J, Betts M, and Jain P: Lack of recall response to Tax in ATL and HAM/TSP patients but not in asymptomatic carriers of human T-cell leukemia virus type 1. J Clin Immunol 2013 (submitted).

26. Roederer M: Spectral compensation for flow cytometry: Visualization artifacts, limitations, and caveats. Cytometry 2001;45(3):194-205.

27. Roederer M and Hardy RR: Frequency difference gating: A multivariate method for identifying subsets that differ between samples. Cytometry 2001;45(1):56-64.

28. Roederer M, Nozzi JL, and Nason MC: SPICE: Exploration and analysis of post-cytometric complex multivariate datasets. Cytometry A 2011;79(2):167-174.

29. Duesberg U, von dem Bussche A, Kirschning C, Miyake K, Sauerbruch T, and Spengler U: Cell activation by synthetic lipopeptides of the hepatitis $\mathrm{C}$ virus $(\mathrm{HCV})$-core protein is mediated by toll like receptors (TLRs) 2 and 4 . Immunol Lett 2002;84(2):89-95.

30. Azakami K, Sato T, Araya N, et al.: Severe loss of invariant NKT cells exhibiting anti-HTLV-1 activity in patients with HTLV-1-associated disorders. Blood 2009;114(15):3208-3215.
31. Hishizawa M, Imada K, Kitawaki T, Ueda M, Kadowaki N, and Uchiyama T: Depletion and impaired interferon-alphaproducing capacity of blood plasmacytoid dendritic cells in human T-cell leukaemia virus type I-infected individuals. Br J Haematol 2004;125(5):568-575.

32. Best I, Lopez G, Verdonck K, et al.: IFN-gamma production in response to Tax 161-233, and frequency of CD4 + Foxp3+ and Lin HLA-DRhigh CD123 + cells, discriminate HAM/ TSP patients from asymptomatic HTLV-1-carriers in a Peruvian population. Immunology 2009;128(1 Suppl):e777-786.

33. Meyers JH, Justement JS, Hallahan CW, et al.: Impact of HIV on cell survival and antiviral activity of plasmacytoid dendritic cells. PLoS ONE 2007;2(5):e458.

34. Brown KN, Wijewardana V, Liu X, and Barratt-Boyes SM: Rapid influx and death of plasmacytoid dendritic cells in lymph nodes mediate depletion in acute simian immunodeficiency virus infection. PLoS Pathogens 2009;5(5):e1000413.

35. Nascimbeni M, Perie L, Chorro L, et al.: Plasmacytoid dendritic cells accumulate in spleens from chronically HIVinfected patients but barely participate in interferon-alpha expression. Blood 2009;113(24):6112-6119.

36. Foussat A, Bouchet-Delbos L, Berrebi D, et al.: Deregulation of the expression of the fractalkine/fractalkine receptor complex in HIV-1-infected patients. Blood 2001;98(6):16781686.

37. Colisson R, Barblu L, Gras C, et al.: Free HTLV-1 induces TLR7-dependent innate immune response and TRAIL relocalization in killer plasmacytoid dendritic cells. Blood 2010;115(11):2177-2185.

38. Al-Fahim A, Cabre P, Kastrukoff L, Dorovini-Zis K, and Oger J: Blood mononuclear cells in patients with HTLV-Iassociated myelopathy: Lymphocytes are highly activated and adhesion to endothelial cells is increased. Cell Immunol 1999;198(1):1-10.

39. Wherry EJ: T cell exhaustion. Nat Immunol 2011;12(6):492499.

40. Blackburn SD, Shin H, Haining WN, et al.: Coregulation of $\mathrm{CD} 8+\mathrm{T}$ cell exhaustion by multiple inhibitory receptors during chronic viral infection. Nat Immunol 2009;10(1):2937.

41. Trabattoni D, Saresella M, Biasin M, et al.: B7-H1 is upregulated in HIV infection and is a novel surrogate marker of disease progression. Blood 2003;101(7):2514-2520.

42. Kozako T, Yoshimitsu M, Fujiwara H, et al.: PD-1/PD-L1 expression in human $\mathrm{T}$-cell leukemia virus type 1 carriers and adult T-cell leukemia/lymphoma patients. Leukemia 2009;23(2):375-382.

43. Abdelbary NH, Abdullah HM, Matsuzaki T, et al.: Reduced Tim-3 expression on human T-lymphotropic virus type I (HTLV-I) Tax-specific cytotoxic T lymphocytes in HTLV-I infection. J Infect Dis 2011;203(7):948-959.

44. Samimi S, Benoit B, Evans K, et al.: Increased programmed death-1 expression on CD4 $+\mathrm{T}$ cells in cutaneous $\mathrm{T}$-cell lymphoma: Implications for immune suppression. Arch Dermatol 2010;146(12):1382-1388.

45. Trautmann L, Janbazian L, Chomont $\mathrm{N}$, et al.: Upregulation of PD-1 expression on HIV-specific CD8 + T cells leads to reversible immune dysfunction. Nat Med 2006;12(10):11981202.

46. Radziewicz H, Ibegbu C, Fernandez M, et al.: Liverinfiltrating lymphocytes in chronic human hepatitis $C$ virus infection display an exhausted phenotype with high levels of PD-1 and low levels of CD127 expression. J Virol 2007;81: 2545-2553. 
47. Day CL, Kaufmann DE, Kiepiela P, et al.: PD-1 expression on HIV-specific T cells is associated with T-cell exhaustion and disease progression. Nature 2006;443(7109):350-354.

48. Nakamoto N, Cho H, Shaked A, et al.: Synergistic reversal of intrahepatic HCV-specific CD8 T cell exhaustion by combined PD-1/CTLA-4 blockade. PLoS Pathogens 2009;5(2): e1000313.

49. Penna A, Pilli M, Zerbini A, et al.: Dysfunction and functional restoration of $\mathrm{HCV}$-specific CD8 responses in chronic hepatitis C virus infection. Hepatology 2007;45(3):588-601.

50. Boni C, Fisicaro P, Valdatta C, et al.: Characterization of hepatitis $\mathrm{B}$ virus (HBV)-specific T-cell dysfunction in chronic HBV infection. J Virol 2007;81(8):4215-4225.

51. Boettler T, Panther E, Bengsch B, et al.: Expression of the interleukin-7 receptor alpha chain (CD127) on virus-specific $\mathrm{CD} 8+\mathrm{T}$ cells identifies functionally and phenotypically defined memory $\mathrm{T}$ cells during acute resolving hepatitis $\mathrm{B}$ virus infection. J Virol 2006;80(7):3532-3540.
52. Topalian SL, Hodi FS, Brahmer JR, et al.: Safety, activity, and immune correlates of anti-PD-1 antibody in cancer. N Engl J Med 2012;366(26):2443-2454.

53. Brahmer JR, Tykodi SS, Chow LQ, et al.: Safety and activity of anti-PD-L1 antibody in patients with advanced cancer. N Engl J Med 2012;366(26):2455-2465.

Address correspondence to: Pooja Jain

Department of Microbiology and Immunology, and the Drexel Institute for Biotechnology and Virology Research Drexel University College of Medicine 3805 Old Easton Road

Doylestown, Pennsylvania 18902

E-mail: pjain@drexelmed.edu 